\title{
Confusion and dependence in uses of history
}

\author{
David Slutsky
}

Received: 1 July 2008 / Accepted: 18 August 2010 / Published online: 1 October 2010

(C) Springer Science+Business Media B.V. 2010

\begin{abstract}
Many people argue that history makes a special difference to the subjects of biology and psychology, and that history does not make this special difference to other parts of the world. This paper will show that historical properties make no more or less of a difference to biology or psychology than to chemistry, physics, or other sciences. Although historical properties indeed make a certain kind of difference to biology and psychology, this paper will show that historical properties make the same kind of difference to geology, sociology, astronomy, and other sciences. Similarly, many people argue that nonhistorical properties make a special difference to the nonbiological and the nonpsychological world. This paper will show that nonhistorical properties make the same difference to all things in the world when it comes to their causal behavior and that historical properties make the same difference to all things in the world when it comes to their distributions. Although history is special, it is special in the same way to all parts of the world.
\end{abstract}

Keywords Natural kind · Essential properties · Explanation · Behavior · Historical properties · Generalizations · Distributions · Causal activity · Historical kinds · Copied kinds · Real kinds · Prediction

\section{Introduction}

Since work by Saul Kripke, Hilary Putnam, and Tyler Burge, philosophers have increasingly assigned ontological status and roles to historical properties in the study of language, psychology, and biology. Enc (1995) argues that the supervenience bases of certain behaviors and psychological states include historical properties.

D. Slutsky $(\varangle)$

Eastern Connecticut State University, Willimantic, CT, USA

e-mail: david.slutsky@gmail.com 
Elder $(1995,1996)$ and Enc (1995) argue that certain behaviors and biological devices essentially include historical properties. Elder (1995, 1996), Griffiths (1996, 1999), and Millikan (1996, 1999, 2000) argue that certain substances and biological devices are members of real or natural kinds, as opposed to conventional or nominal ones, in virtue of their historical properties.

Although the arguments of Elder, Enc, Griffiths, and Millikan contain interesting differences, they also share the common view that historical properties mark an important difference between the biological and the nonbiological world-and, on many related views, between the psychological and the nonpsychological world. This paper is part of a larger project designed to show that historical properties make no more or less of a difference to biology or psychology than to chemistry, physics, or other sciences. Although historical properties indeed make a certain kind of difference to biology and psychology, this paper will show that historical properties make the same kind of difference to geology, sociology, astronomy, and other sciences. The view that history makes a special difference to biology or psychology leads to two problems that we can call (1) confusion and (2) dependence. The confusion problem involves an alleged analogy proposed by Elder, Griffiths, and Millikan between an essential role that historical properties serve for 'historical kinds' and an essential role that internal properties serve for 'eternal kinds'. A distinction by Waters (1998) between generalizations about distributions, on the one hand, and generalizations about causal regularities, on the other hand, will help make clear that historical properties serve the same roles for historical and eternal kinds and that nonhistorical properties serve the same roles for historical and eternal kinds. Whether historical properties serve an epistemic role in making predictions or generalizations about causal behavior is a contingent matter both for biology and psychology, on the one hand, and for any other science, on the other hand. In contrast, historical properties serve an essential role in making generalizations about distributions in all of the sciences_-not just biology and psychology. Similarly, nonhistorical properties serve an essential role in making generalizations about causal behavior in all of the sciences, not just those sciences "harder" (or "softer") than biology and psychology. I will discuss these roles and how they relate to natural kinds in Sect. 2 (addressing the confusion problem, where the confusion is between what kind of properties explain generalizations about distributions and what kind of properties explain generalizations about causal regularities).

Closely related to the confusion problem, the dependence problem involves a difficulty in separating the epistemic grounds or reasons that we have for making certain predictions and generalizations, on the one hand, from the ontological grounds or features of the world that make such predictions and generalizations successful, on the other hand. Elder and Enc both argue that historical properties have ontological significance because of the indispensable role that these properties seem to play in the warranted predictions and generalizations about behavior that we make with frequent success. The problem is that the historical properties are not really indispensable. Their apparent indispensability depends on facts about us and such things as the extent of our knowledge, ignorance, and technological development. This dependence on the (contingent and epistemic) use of historical properties is a problem insofar as ontological factors such as the essential properties of things outside of our minds are not supposed to depend on contingent facts about our minds. I will discuss this problem in Sect. 3. 


\section{Confusion}

\subsection{Introduction}

Do products of natural selection such as tiger hearts and the mating dances of stickleback fish constitute natural kinds? On the one hand, these products are groupings over which we can run informative and warranted inductions with non-accidental success. This is a common feature of natural kinds. On the other hand, the reason why the members of these groupings are like one another is that they share a history of being copied from previous members under environmental selection pressures. This is a less common feature of natural kinds. The reason why members of traditional natural kinds such as water and gold are like one another is that they share a common micro or internal structure rather than a common history. The products of natural selection show that the first common feature of natural kinds about induction may be more important than the second common feature about microstructure in distinguishing real or natural kinds from conventional or nominal kinds. Hearts and mating dances are not conventional groupings even though the reasons that members of these groups are like one another are different from the reasons that members of groupings of water and gold are like one another.

Elder (1995, 1996), Griffiths (1996, 1999), and Millikan (1996, 1999, 2000, Chap. 2), argue in this manner for a revision in the traditional account of natural kinds. Biological devices such as organs and behaviors that result from a history of selection and copying constitute members of what Elder calls 'copied kinds' and Millikan calls 'historical kinds'. Elder and Millikan aim to broaden the category of natural kind so that copied or historical kinds, on the one hand, and more traditional natural kinds, on the other hand, are two kinds of real kind. One way to distinguish one real kind from another is by the reason or principle that accounts for why their respective members are like one another. These reasons or principles explain the likenesses and provide the essences of the kinds. In Millikan's terms, the essence of a real kind provides the ontological ground for the successful inductions we can make about its members. In Elder's terms, the essence of a real kind explains why we are warranted in making successful inductions about them. On both of their views, the reason why members of historical kinds are like one another is that they share certain historical properties about past copying and selection. Elder and Millikan believe that the essences of historical kinds consist in these historical properties.

Let us follow Millikan in calling traditional natural kinds 'eternal kinds'. The essences of eternal kinds consist in their respective internal microstructures that provide the reasons why the members of the kind are like one another. According to Elder, Griffiths, and Millikan, certain historical properties of historical kinds are analogous to certain microstructural properties of eternal kinds. These analogues are supposed to provide the respective ontological grounds and epistemological warrant for successful inductions about historical and eternal kinds.

There are three main problems with the analogy that Elder, Griffiths, and Millikan propose. First, historical properties play the same role in explaining certain likenesses among members of eternal kinds as they play in explaining certain likenesses among members of historical kinds. Historical properties serve the same role in explaining 
what we can call the distributive likenesses of both historical and eternal kinds. Second, nonhistorical properties play the same role in providing the ontological grounds for successful inductions about the causal behavior of members of both eternal and historical kinds. Third, whether historical or nonhistorical properties play an epistemological role in warranting inductions about the causal behavior of historical or eternal kinds reflects contingent facts about human knowledge, ignorance, and technological development, not the essential properties of real kinds.

These three problems with the alleged analogy between historical and nonhistorical properties highlight a confusion between two different kinds of generalizations that Waters (1998) calls distributions and causal regularities. Historical properties explain generalizations about distributions_-inside and outside of biology. Similarities in nonhistorical properties explain generalizations about causal regularities-inside and outside of biology.

\subsection{History explains certain generalizations: the distributive ones}

Millikan chose the word 'eternal' for eternal kinds because she believes that the historical location of their members in time and space plays no role in explaining the likenesses among their members. However, these members are just as much the products of historical processes as the members of historical kinds are. There are specific historical reasons why the vast majority of glaciers, oceans, rivers, and lakes on the Earth contain a compound comprised of two hydrogen atoms and one oxygen atom that are chemically bonded in a certain way. The vast majority of liquid containers on the Earth contain a liquid with this microstructure as a result of a historical process that dates back to the big bang, with past properties of our galaxy, solar system, sun, atmosphere, and planetary development playing key roles (Kasting and Catling 2003). Of course, the laws of chemistry and physics played key roles in these historical processes. Nonetheless, in order to explain why so many liquids on the Earth have a similar microstructure and why so many Earthly cavities contain liquids that have a similar microstructure, we need to appeal to the historical processes through which various natural laws and elements resulted in this distribution of liquids.

In addition, the distributions of members of eternal kinds depend on historical and ongoing processes in which environmental properties play crucial roles. For instance, the distribution of water on the Earth depends on the intricacies of the greenhouse effect, the water cycle, the organic carbon cycle, and the carbonate silicate cycle. The presence of certain gases in the atmosphere helps maintain temperatures that make possible a dynamic equilibrium between the retention of certain forms of water and the production of certain gases. The current distribution of different forms of water on the Earth is highly contingent on past and ongoing environmental processes (Kump et al. 2004, Chaps. 3-5, 8). ${ }^{1}$

Historical location in time and space indeed plays an important role in explaining similarities in both internal structures (such as $\mathrm{H}_{2} \mathrm{O}$ molecules) and dispositions (such

\footnotetext{
1 See McKitrick (2003) for some of the metaphysical details of how what appear to be intrinsic properties may really depend on extrinsic properties.
} 
as the goal-directed behavior that results from either operant conditioning or natural selection). ${ }^{2}$ Historical properties explain and provide the ontological ground for generalizations about the distributions of things that share such similarities. Historical properties serve this role for generalizations about the distributions of water and gold as well as stickleback fish and tiger hearts. To be sure, it is highly unlikely that any two samples of water or gold will share exactly the same internal properties just as it is highly unlikely that any two members of a biological species or any particular organ of two members of the same biological species will share exactly the same internal properties. The differences that accompany the similarities in both kinds of cases are due to contingent features of the historical processes that lead to the distributions.

In both kinds of cases, the historical processes make possible successful generalizations about distributions of certain similarities. For instance, the next human we see is likely to have two legs and a heart with four chambers, and the next Earth ocean or lake that we analyze is likely to contain $\mathrm{H}_{2} \mathrm{O}$, for the same respective historical reasons. The main point that Waters (1998) helps make especially clear is that similarities in the nonhistorical properties of legs, hearts, and samples of water explain and provide the ontological grounds for any successful generalizations that we make about regularities in their causal behavior. The analogy that Elder, Griffiths, and Millikan propose between the historical properties of historical kinds and the internal properties of eternal kinds confuses distributive and nondistributive questions about why members of real kinds are like one another. ${ }^{3}$ If we keep these different questions separate, we can see that historical properties serve the same roles for all real kinds, and that nonhistorical properties serve the same roles for all real kinds.

\subsection{Nonhistorical properties provide the ontological grounds for generalizations about the causal behavior of members of eternal and historical kinds}

Although historical information about the distributive properties of a real kind may help us make successful generalizations about the causal behavior of the kind members, it only does so by providing us with information about the nonhistorical properties of those members (Waters 1998, pp. 16-17, 19-20). When it comes to explaining generalizations about causal regularities, as opposed to distributions, historical properties serve only a heuristic role. Historical properties may tell us why kind members share similar properties. However, as we will see in more detail in Sect. 3, the nonhistorical

\footnotetext{
2 See Waters (1998, pp. 14-15, 23-25) on how history explains distributive generalizations about the two different kinds of similarities. Notice that Millikan (1999, pp. 48-49, 54-55); Millikan (2000, pp. 18-20, 23-25) seems to focus on generalizations about tokens of what Waters calls 'theoretical kinds'. Nonetheless, it is clear that Millikan intends her claims also to apply to more broad functional cases, such as Enc's example of the play bow of social carnivores (1995, p. 539).

3 The idea here about the connection between history and generalizations about distributions as opposed to generalizations about causal regularities is similar to Sober's (1995) claim that although natural selection explains the frequencies of traits in populations, more proximate and developmental facts about individual organisms explain why they each have the traits that they do. For related points, see Miller (1978), Garfinkel (1981), and Enc and Adams (1992).
} 
properties of those members are causally responsible for similarities in their behavior. ${ }^{4}$ Why do so many liquids in different ocean basins on Earth share a similar molecular structure, on the one hand, is a distributive question about certain features of the history of the Earth's mantle, atmosphere, and planetary bombardment. Why do so many liquids in different ocean basins on Earth boil and freeze at certain temperatures, on the other hand, is a nonhistorical question about causal regularities in the behavior of those liquids.

To be sure, the causal inefficacy of historical properties is confirmed on virtually all the major accounts of causation (e.g., manipulability/intervention, difference making, contrastive, ANOVA, etc.). Experiments designed to test the causal efficacy of historical properties will always produce negative results. Basically, if you hold everything nonhistorical the same and change only historical properties, you will never get any causal difference (that is not due to probabilistic dispositions of the nonhistorical properties). If there is some causal pathway alleged to include causally active historical properties, whenever we construct the same pathway with different historical properties we never get different effects; any different effects we do get will only be the same different effects determined by the probabilistic dispositions of causally active nonhistorical properties. ${ }^{5}$ When it comes to causal behavior above the subatomic level, ${ }^{6}$ nonhistorical properties do all the causal work. Just to be clear, the idea is that since nonhistorical properties are causally responsible for any and all causal behavior, historical properties can only be helpful in making successful predictions or generalizations about causal behavior if and when they serve a strictly heuristic role by providing information about the nonhistorical properties doing the real causal work. $^{7}$

Let us return to a concrete example that illustrates the essential role that historical properties serve (for all real kinds) and a related concrete example that illustrates the essential role that nonhistorical properties serve (for all real kinds). Why do so many reproductively isolated freshwater stickleback fish have less body armor in terms of fewer lateral plates and smaller dorsal and pelvic spines than marine sticklebacks? Part of the answer to this question about the distribution of stickleback bones begins with the end of the last ice age when melting and receding glaciers left behind thousands of lakes and streams for sticklebacks to colonize (Bell and Foster 1994). Differences in predators, evasion options, and calcium availability created selection pressures for fewer and

\footnotetext{
4 To appeal to historical properties as the ontological ground for successful inductions about nondistributive generalizations is to commit a systematic 'modest embarrassment' on my understanding of Boyd's terms (1999b, pp. 70, 74-75).

5 See Slutsky (2001) for related discussion and argument.

6 According to standard accounts of quantum mechanics, historical properties seem to have nonlocal effects on particles entangled in quantum mechanical states. However, due to quantum decoherence, all biological and psychology subjects are too large to become entangled in this way that seems to confer causal power on the historical properties of certain subatomic particles.

7 This claim does not require determinism. We can restate it in terms of the probabilistic dispositions of any causally active nonhistorical properties. See Prior et al. (1982). As Walsh (1999) makes clear, environmental properties in many contexts either affect causal powers of intrinsic properties or make causal contributions themselves. Nonetheless, in no contexts do historical properties ever affect causal powers or make causal contributions themselves. See also Kim (1991).
} 
smaller bones. The isolated populations of sticklebacks adapted quickly to their new environments in a remarkable display of parallel evolution (McKinnon and Rundle 2002; McKinnon et al. 2004).

However, suppose we make generalizations, not about the distribution of stickleback bones, but about how marine sticklebacks survive encounters with soft-mouthed predators and freshwater sticklebacks survive encounters with large invertebrate predators. In these cases, the size and number of stickleback spines and plates, along with other nonhistorical properties such as the size and shape of predator gapes, is causally responsible for the regularities in the encounters.

For one more example, geologists searching for oil and natural gas generally do not conduct seismic surveys over areas dominated by igneous or metamorphic rocks. Rather, they conduct their surveys over certain areas dominated by sedimentary rocks. The distribution of oil and gas throughout the Earth is determined by historical processes that transform biomass and organic materials into hydrocarbons during historical processes involving various pressures and endothermic reactions. Heavy layers of sediment foster these historical processes. Such geological processes combine over time with others such as maturation and migration, resulting in the distributions of oil and gas in the Earth today (Press et al. 2003, Chaps. 8, 21, 22). The historical properties of the aforementioned geological processes explain successful generalizations about where we can and cannot find Earthly oil and gas. Nonetheless, only certain nonhistorical properties of oil and gas explain generalizations about their causal behavior. Similar claims with different details apply to the distribution and causal behavior of all other substances in the universe, including gold in the Earth, planets in solar systems, stars and solar systems in galaxies, and gases in regions of interstellar space.

\section{Dependence}

\subsection{Introduction}

Another way of expressing one of the main points in Sect. 2 is that when we ask for an explanation for generalizations about distributions, we are really asking an historical question about how - through what historical processes - did the distributions come about. In this sense, we can reasonably contend that the relevant historical properties are essential to distributions. Many people have defended this contention about population level phenomena, with distributions being one way we talk about features of populations. In contrast, one of the assumptions in Sect. 2 is that historical properties are not essential to causal activity, causal behavior, causal regularities, or explanations of generalizations about causal matters. However, as noted in Sect. 1, many people claim that historical properties are essential to biological and psychological subjects of various kinds. For instance, Elder and Enc both argue that the only way to explain the successful predictions and generalizations we frequently make about functional behavior is to revise our understanding of the supervenience bases of that behavior to include historical properties. They both argue that since historical properties are indispensable to making successful predictions and generalizations about certain behaviors, we should revise our understanding of the supervenience base of 
those behaviors essentially to include historical properties. Here is the general form of argument used most clearly by Enc $(1995)$ and Elder $(1995,1996)^{8}$ :

The alleged indispensability of historical properties argument

(1) If certain historical properties are indispensable to certain scientific practices about behavior (predicting, generalizing, and/or explaining successful predictions and generalizations), then those historical properties are both part of the supervenience base of and are essential to that behavior.

(2) Certain historical properties are indispensable to certain scientific practices about certain behaviors (predicting, generalizing, and/or explaining successful predictions and generalizations).

(3) Hence, certain historical properties are both part of the supervenience base of and are essential to certain behaviors. ${ }^{9}$

It is important to distinguish between two different interpretations of "indispensable" in this argument. First, we could interpret indispensable to mean indispensable always, everywhere, for everyone and anyone. We can call this interpretation "idealized agent indispensability", since the indispensability involved would apply even to idealized agents with complete knowledge of everything. Second, we could interpret indispensable to mean indispensable to a particular agent in a particular place at a particular time. We can call this interpretation "actual agent indispensability", since it involves actual agents such as us.

On the idealized agent interpretation of indispensability, premise 2 in the argument above looks false. It is not clear that historical properties are not always in principle dispensable when we have adequate knowledge of all relevant nonhistorical properties (including intrinsic properties as well as contemporaneous relational and extrinsic properties). If our knowledge of relevant nonhistorical properties is not ideal, then knowledge of historical properties may serve a heuristic role by providing information about the relevant nonhistorical properties. In that case, however, the historical properties are not really indispensable. Similarly, on the actual agent interpretation of indispensability, premise 1 in the argument above looks false. It is not clear why or how the contingent needs of particular agents could reveal the ontology or essential properties of things in the world.

In Sect. 3.2, I will criticize the idealized agent interpretation of indispensability by presenting three different kinds of evidence for denying the truth of premise 2 on that interpretation. In Sect. 3.3, I will criticize the actual agent interpretation of indispensability by questioning the connection (presented in premise 1) between contingent epistemic needs in the minds of scientific agents and the essential properties of biological and psychological subjects outside the minds of those agents.

\footnotetext{
8 See also, for instance, Griffiths (1997) and Boyd (1999c).

9 Please remember that this argument focuses on scientific practices, such as predictions and generalizations, about (causal) behavior. In contrast, scientific practices that focus on generalizations about distributions or frequencies of traits in populations, and scientific practices that focus on taxonomizing (distributions of) traits, organisms, populations, or species in terms of phylogenetic history, for instance, require the historically oriented approach/analysis provided and discussed in Sect. 2. Classifying behavior (historically or otherwise) for the purposes of operant conditioning, or for making nondistributive predictions or generalizations, however, does indeed fall within the purview of this argument.
} 


\subsection{The idealized agent interpretation of indispensability}

There are three different kinds of evidence that, taken together, count against the truth of premise 2 in the argument above. We can label them exhibits (A), (B), and (C). Roughly, exhibit (A) provides metaphysical evidence, exhibit (B) provides empirical evidence, and exhibit (C) provides epistemological (and empirical) evidence that premise 2 of the argument above is not true on the idealized agent interpretation of indispensability.

Exhibit (A) is the doctrine known as the causal completeness of physics, or the causal closure of the physical (Papineau 2001, 2009). Above the subatomic level, physics does not recognize or allow for the causal efficacy of historical properties. Biological and psychological subjects do not exist below the atomic level. According to the causal completeness of physics, the causal activity of biological and psychological subjects depends wholly on nonhistorical properties. ${ }^{10}$

This is not the place to undertake a detailed analysis of the metaphysics of historical properties. However, a few comments will suffice both to provide grounds for thinking that historical properties are not physical and to elucidate the aforementioned claims about exhibit A. The notion of historical properties requires a conception of persistence. In order for something to have historical properties, that thing must have persisted from one time to another; in order for something in the present to have historical properties, that thing must have persisted from some time in the past to the present. On an endurance account of persistence, the historical properties of something at a time $\mathrm{T}$ are really facts or information about the nonhistorical properties of that thing before time $\mathrm{T}$. In other words, the historical properties of something at a time $\mathrm{T}$ consist in facts or information about the past intrinsic properties, past contemporaneous relational properties, and past contemporaneous extrinsic properties of that thing before T. Historical properties themselves leave no physical trace on their property bearers. The physical sciences cannot measure, record, or detect them. The only place in the world where we can find historical properties is in the brains/minds of the people who have beliefs (or other psychological states) about them. However, the neurological/mental states of people that either allow those people to think about historical properties or that consist in those people thinking about historical properties are different from the historical properties themselves. In this sense, on the endurance account of persistence, historical properties are not physical. ${ }^{11}$

On a perdurance account of persistence, there really is no such thing as historical properties. According to perdurance, what we ordinarily think of as the historical properties of something are really the intrinsic, relational, or extrinsic properties of earlier (or different) temporal parts of that thing. On either of these two major accounts of persistence, historical properties are excluded by the causal completeness of physics

\footnotetext{
10 Recall that, as argued in Sect. 2, the frequency of traits in populations or distributions is a different matter-in such cases, historical properties are highly relevant if not essential and/or indispensable.

11 Shoemaker (1980) seems to agree. See in particular his remarks on "mere-cambridge" properties.
} 
because they are either not physical (according to endurance) or not really historical (or according to perdurance). ${ }^{12}$

Exhibit (B) consists of evidence showing that, in principle if not in practice (and in the future if not in the present), we can successfully predict and explain causal behavior by appealing solely to nonhistorical properties. The first part of exhibit (B) involves the Synthetic Telepathy joint research programs conducted by teams at the University of California at Irvine, Carnegie Mellon University, and New York University. This U.S. military funded project (the Department of Defense Multi-disciplinary University Research Initiative, MURI, program) involves basic research needed to make possible brain-computer interfaces for decoding thoughts from brain scans and communicating them to intended targets. Numerous military field applications include communication without vision or speech, mental control of machinery/weaponry, lie detection, and other forms of mind reading (D'Zmura et al. 2009; Srinivasan et al. 2009).

The second part of exhibit (B) involves Jack Gallant's research at UC Berkeley that uses computational encoding models accurately to interpret, decode, and predict brain activity. The popular press picked up one of his labs papers on this matter (Kay et al. 2008) and reported it widely. Gallant uses his models to decode brain activity, providing a direct and principled way to do "brain reading", and to build brain-machine interfaces and neural prosthetics (Naselaris et al. 2009). Similarly, one part of Kendrick Kay's research (working in collaboration with Gallant's lab) at UC Berkeley is designed to decode brain activity in order to determine what people are perceiving. For instance, one of Kay's papers (co-authored with Gallant) has the telling and provocative title, "I can see what you can see" (Kay and Gallant 2009).

The third part of exhibit (B) involves John-Dylan Haynes research as the Professor for Theory and Analysis of Large Scale Brain Signals at the Bernstein Center for Computational Neuroscience at Humboldt University of Berlin as well as a Senior Researcher (for the research group "Attention and Awareness") at the Max Planck Institute for Human Cognitive and Brain Sciences in Leipzig, Germany (Haynes and Rees 2006; Haynes et al. 2007; Haynes 2008, 2009). Haynes is working similarly towards predicting people's thoughts with scans of brain activity that will allow for such things as detection of deception, the mental control of computers and artificial prostheses, and even involuntary market research.

The fourth part of exhibit (B) consists of work at Carnegie Mellon University by Marcel Just, Tom Mitchell, and colleagues involving development of statistical algorithms both that analyze fMRI data and that learn to identify and track the cognitive processes that give rise to the fMRI data. This kind of neuroimaging uses classifiers to find stimulus unique patterns of brain activation both to form theories that connect cognitive processes with brain functions and that allow, or that teach, algorithms/machines to detect cognitive states (Just et al. 2010; Palatucci et al. 2009; Shinkareva et al. 2008;

\footnotetext{
12 I rely here on a contentious but not uncommon connection between endurance and presentism, on the one hand, and perdurance and eternalism, on the other hand. For relevant arguments, see Merricks (1994, 1995, 1999) as well as Carter and Hestevold (1994). Notice that the alleged subjects of historical properties can include planets, continents, ecosystems, habitats, species, and individual organisms.
} 
Mitchell et al. 2008). We can follow others in accurately characterizing this work as a form of "mind reading" and human psychology recognition/detection by machines.

Further parts of exhibit (B) could involve some of the reductionist research programs in neuroscience. ${ }^{13}$ One thing most if not all of them have in common along with the other parts of exhibit (B) is an absence of historical properties in their research. Enc and Adams (1992), Enc (1995), Elder (1995, 1996) and Ariew (2003) all affirm premise 2 from the argument above and claim that we cannot successfully predict or explain the causal behavior of certain psychological and biological subjects without adequate understanding of the relevant historical properties leading up to that behavior. The research programs summarized in exhibit (B), even in their infancy, seem to provide evidence that calls into question the truth of premise 2 .

Exhibit (C) involves a particular criticism of evolutionary psychology that Davies (1996), Grantham and Nichols (1999), and Boyd (2001), seem independently to have developed and converged upon. These authors discuss two different methods or approaches to research that evolutionary psychologists explicitly use. One method focuses on using evolutionary considerations and historical speculations about past selection pressures to predict the existence and nature of mental modules and psychological capacities. The other method focuses on independently identified mental modules and psychological capacities discovered and confirmed by nonhistorical studies, and then proceeds to provide evolutionary explanations for them. The aforementioned critics concede (and even argue) that there are compelling arguments for the second, explanatory method/approach, from which we can learn a great deal. In contrast, the critics argue that the first, predictive method/approach is prone to develop unjustified inferences and Panglossian forms of adaptationism.

To be sure, the first approach — characteristic of allegedly received wisdom-seems to get things backwards. It is only through the study of nonhistorical properties that we can obtain knowledge of historical properties in the first place as we make inferences to facts about the past (Davies 2001, pp. 55-56, Chap. 5). Work by David Kingsley's lab at Stanford University (along with colleagues elsewhere) on stickleback fish illustrates this claim and provides evidence of several instances of it. Kingsley studied the genetic changes behind the anatomical and subsequent/accompanying behavioral differences between freshwater and marine sticklebacks summarized in Sect. 2.3, such as the loss of hind fins, pelvic fins, and body armor in freshwater sticklebacks across the Northern hemisphere. By selective breeding of sticklebacks from different populations through mating and in vitro fertilization, Kingsley identified mutations in particular genes that still produce the same proteins, but produce them in different parts of the fish. In repeated tests on freshwater sticklebacks collected from different local and global reproductively isolated populations, Kingsley similarly found causal responsibility for other adapted traits through mutations in a single gene that did not alter the protein produced by the gene but rather the locations in the developing fish where the gene produced the relevant protein (Colosimo et al. 2004; Shapiro et al. 2004; Shapiro et al. 2006; Chan et al. 2010).

\footnotetext{
13 For instance, see John Bickle's account of the mental in terms of molecular and cellular cognition (Bickle et al. 2003; Bickle 2006a,b, 2007, 2008).
} 
These and similar experiments on the nonhistorical properties of live fish explain and produce detailed knowledge of the speciation and parallel evolution from marine to freshwater sticklebacks beginning 15,000 years ago and occurring in similar ways today (McKinnon et al. 2004). These kinds of nonhistorical data and analyses include work in quantitative genetics, genomics, population genetics, molecular evolution, field studies, and developmental biology. The nonhistorical data collected with this work and analyzed by Kingsley, members of his lab, colleagues, and Kingsley's former students with their own labs provide insights into how changes occur in evolution generally and in micro versus macroevolution in particular (Colosimo et al. 2004, 2005; Shapiro et al. 2006; Shapiro et al. 2009; Kingsley and Peichel 2007; Miller et al. 2007; Hendry et al. 2009; Kitano et al. 2009; Chan et al. 2010; Schluter et al. 2010). We will elaborate on this approach in Sect. 3.3 (as well as in Sects. 3.3.1 and 3.3.2), along the lines of exhibit (C) in this current Sect. 3.2, while discussing scientific practices of using nonhistorical properties in order both to understand behavior and the contemporary world, and to discover and understand the relevant historical properties that led up to the contemporary world including much of the behavior in it.

\subsection{The actual agent interpretation of indispensability}

Recall the general indispensability argument from Sect. 3.1:

(1) If certain historical properties are indispensable to scientific practices about behavior (predicting, generalizing, and/or explaining successful predictions and generalizations), then those historical properties are both part of the supervenience base of and are essential to that behavior.

(2) Certain historical properties are indispensable to scientific practices about certain behaviors (predicting, generalizing, and/or explaining successful predictions and generalizations).

(3) Hence, certain historical properties are both part of the supervenience base of and are essential to certain behaviors.

In Sect. 3.2, we used the idealized agent interpretation of indispensability to argue that premise 2 is false. In this section, we will use the actual agent interpretation of indispensability to argue that premise 1 is false. Although some scientists may need to appeal to history in their attempts to explain behavior and their warranted success in predicting it, this need presumably changes in accordance with their knowledge, ignorance, and technology. It seems a plausible conjecture that scientific explananda do not change in accordance with scientists' contingent explanans. ${ }^{14}$ The essential properties and the supervenience bases of behavior should not change in accordance with the means that scientists use to predict and explain it. In that case, the need to appeal to history in scientific practice does not constitute sufficient grounds to expand supervenience bases or alleged essences to include historical properties.

If historical properties are in principle dispensable in engaging in and understanding our predictive and explanatory practices about behavior, then we may want to ask why

14 Of course, explanans may make causal contributions to explananda. The assumption here is that they make no noncausal contributions. See Boyd (1992). 
they are such a reliable guide in making accurate predictions. One way to answer this question is to remember that relying on historical properties often leads to inaccurate predictions and to exceptions to otherwise successful generalizations. The reason why historical properties are not always reliable is that they do not always provide accurate information about nonhistorical properties (Lauder 1995; Grantham and Nichols 1999, pp. 58-61). The reason why historical properties are often reliable is that they do often provide accurate information about nonhistorical properties (Boyd 1999a, pp. 166-167; 1999b, pp. 81-84; Saidel 2001, pp. 153-156). It seems a plausible conjecture that these co-variations are no accident. Nonhistorical properties provide the ontological ground for what happens, and for what we can count on to happen, in the future (Dretske 1998). ${ }^{15}$

We can elucidate this argument (against the actual agent interpretation of the indispensability argument) and illustrate it with both imaginary and actual examples. Let us begin with an imaginary example. Suppose that, at a time T, historical properties are not indispensable to the predictions and explanations made by a group of scientists called "S3" who study the mating behavior of stickleback fish. So, at time T, we cannot use the indispensability argument to conclude that historical properties are essential to and part of the supervenience base of the fish behavior that $\mathrm{S} 3$ is studying. Suppose further that at a later time $\mathrm{T}+\mathrm{n}, \mathrm{S} 3$ loses a great deal of its data and equipment (such as fish tanks, computer hard drives containing digital recordings and analyzed data about stickleback courtship, etc). In addition, the same storm that damaged S3's data and equipment also caused a series of tragic electrical accidents that damaged the memories of the scientists in S3. Fortunately, some dusty biology books by Tinbergen and others that contain reports of fossil records, past observations of and experiments on live fish, and evolutionary arguments, escaped damage from the storm. So at time $\mathrm{T}+\mathrm{n}$, certain historical properties (about stickleback courtship discussed in those books) that were not indispensable to S3's predictions and explanations of fish behavior at time $\mathrm{T}$ become indispensable at time $\mathrm{T}+\mathrm{n}$. So we can use the indispensability argument to conclude that historical properties are essential to and part of the supervenience base of fish behavior at $\mathrm{T}+\mathrm{n}$ but not at $\mathrm{T}$. If no scientists other than $\mathrm{S} 3$ study sticklebacks, it seems that, according to the indispensability argument, whether historical properties are essential to stickleback behavior depends on whether a storm happens to cause various amounts of damage, which seems to provide grounds for a reductio against the actual agent interpretation of the indispensability argument.

We can further elucidate and illustrate this line of argument (against the actual agent interpretation of the indispensability argument) with some actual examples. Deborah McLennan, Professor in the Department of Ecology and Evolutionary Biology at the University of Toronto, used behavioral and morphological data (collected in the field and the lab by herself and others) to develop a stickleback phylogenetic tree that depicts genealogical relationships among various stickleback and related species (McLennan et al. 1988; McLennan and McPhail 1989a,b; McLennan 1991, 1993). With her tree in hand and using such considerations as comparisons with past members of the same clade, McLennan compared the respective historical properties regarding

$\overline{15}$ See also Sect. 3.2 as well as Sect. 2.3, especially note 7. 
male nuptial coloration and made successful predictions about it. For instance, one main prediction is that red coloration on the ventrolateral surfaces of males should either be more intensely red and/or positioned so as to be more visible to females during courtship mating dances than before or after them. Collected data confirm McLennan's predictions. To be sure, Brooks and McLennan (1991) argue at length for a version of the indispensability argument regarding the genealogy and phylogeny of sticklebacks (and other species) in order successfully to predict, explain, and understand their behavior. So, according to the indispensability argument, historical properties are essential to, and part of the supervenience base of, stickleback mating behavior.

However, suppose that McLennan had become an investment banker (instead of a scientist studying the evolution of courtship communication), and had never made those successful predictions. Suppose further that no one else had used historical properties to make those predictions that she in fact did make. As it turns out, actual scientists before and after McLennan's studies had already collected the data that confirmed her predictions with nonhistorical properties simply by carefully observing and experimenting with sticklebacks (Pelkwijk and Tinbergen 1937; Tinbergen 1951, 1952; Wilz 1970; Wooton 1973, 1984; Rowland 1984, 1994; Rowland and Sevenster 1985; Milinski and Bakker 1990; Bakker and Milinski 1991, 1993; Fitzgerald 1993; Rowe et al. 2004). Since the actual agent interpretation of the indispensability argument requires historical properties actually to be indispensable to actual scientists (premise 2 of the argument), we cannot use it to conclude that any historical properties are essential to any causal behavior if the work of no actual scientists makes premise 2 true. Of course, we cannot infer that the conclusion of the indispensability argument is false by showing that (the antecedent in the conditional in) premise 2 of the argument is false-both because any such conclusion would be based on an invalid inference and because there do happen to be plenty of scientists around to make versions of premise 2 true. Nonetheless, the first premise of the actual agent interpretation of the indispensability argument remains implausible because it inappropriately makes the essential properties of things such as the behavior of organisms living around the Earth depend on the contingent practices of scientists who may or may not have the allegedly requisite thoughts about those organisms-such as those involved in McLennan becoming a scientist rather than an investment banker.

To be sure, Rowe et al. (2004) provide an incredibly detailed account of stickleback nuptial coloration using entirely nonhistorical sciences. ${ }^{16}$ They analyze their data and then propose/suggest/request evolutionary explanations of them. In contrast to McLennan (McLennan et al. 1988; McLennan and McPhail 1989a,b; McLennan 1991, 1993), Rowe et al. (2004) did not use historical comparisons with past members of the same clade to predict details of stickleback coloration. Rather, they simply studied (nonhistorically) live stickleback coloration in great detail, and include/suggest/request speculation about the coloration of past family members in evolutionary explanations of their detailed nonhistorical findings. This method shares much in

16 See also Milinski and Bakker (1990) and Bakker and Milinski (1991, 1993). Rowland (1994) summarizes
much of the literature and McLennan (2007) covers more recent advances in the context of earlier literature. 
common with the one defended by Davies (1996), Grantham and Nichols (1999), and Boyd (2001) in Exhibit (C) from Sect. 3.2.

Actual and intriguing examples are not hard to find. Ishikawa and Mori (2000) and Ishikawa et al. (2006) identify and discuss a unique mating dance performed by Japan Sea stickleback fish that differs from the mating dance performed by Pacific (and Atlantic) Ocean sticklebacks. The traditional mating dance performed by Pacific sticklebacks is known as the "zig zag" dance. Ishikawa and Mori call the different mating dance of Japan Sea sticklebacks the "lateral display". Kitano et al. (2007, 2008) identify and discuss the same mating dance of Japan Sea sticklebacks, though they give it the possibly more descriptive name of the "rolling dance". None of these scientists started out knowing any evolutionary or other history of the rolling dance. No one knows what it was selected for, what it was an adaptation to, how it increased fitness or what past survival problem it helped solve. Nonetheless, these scientists easily and clearly identified it as courtship behavior. With a bit of observation and experiment, these and other scientists could see that males prepare a nest before they perform the dance, that females frequently follow males to their nest and spawn after males perform the dance, and that male fertilization follows the female spawning after the dance.

In contrast to the claim that we need to know the history of this behavior in order successfully to predict and explain it, Rowe et al. (2004) and Kitano et al. (2007, 2008) first identify and understand the subtle details and dynamics of this behavior using nonhistorical sciences, and then-as a second step-they include, suggest, and/or request evolutionary explanations for the behavior. In addition, as described in exhibit (C) toward the end of Sect. 3.2, one of the leading approaches to providing such explanations uses nonhistorical methods and nonhistorical properties involving hybrid mating and genomic tools/analysis to learn about the genetic architecture of evolutionary changes in courtship behavior, including the mechanisms underlying evolutionary changes in neural circuitry. This work follows the steps of Kingsley's lab in using stickleback genetic and genomic studies to learn about the molecular basis of vertebrate evolution more generally (Colosimo et al. 2004, 2005; Shapiro et al. 2006; Shapiro et al. 2009; Kingsley and Peichel 2007; Miller et al. 2007; Kitano et al. 2009; Schluter et al. 2010).

\subsubsection{Enc's (1995) version of the indispensability argument: a brief case study}

Enc (1995) argues for a paradigm shift in how we understand certain classes of behavior. He wishes to clarify and contrast "molar" behavior with behavior that consists in specific muscle movements and precisely describable limb trajectories. Enc argues that a version of the indispensability argument applies to molar behavior. Molar behavior consists in "units of behavior" that are plastic and goal directed. His main example is the behavior that results from operant conditioning on a pigeon to peck a key in response to a flashing light. In this example, experimenters use the release of food as reinforcement when key pecks correlate with the flashing light. Such molar behavior is functional and is realized by many different muscle movements and limb trajectories. Enc contends that molar behavior is the proper explananda of psychology. He argues that historical properties (in this case about the conditioning process on the 
pigeon) are indispensable to explaining molar behavior and to classifying behavior for the purposes of operant conditioning. His arguments fall prey to the problems that plague both the idealized agent and the actual agent interpretations of the general indispensability argument.

The success of Enc's arguments depends on unfairly restricting the competing candidates for the explanans of molar behavior. His unfair restrictions point toward the apparent indispensability of historical properties. Revising the competing candidates more fairly reveals the dispensability of historical properties. Enc proposes two main candidates for the explanans of molar behavior. The first candidate consists in the nonhistorical properties of the muscle movements and limb trajectories involved in the behavior. The second candidate consists in the historical properties involved in the conditioning, copying, or selection processes that led to the molar behavior. Enc argues that since the first candidate does not provide us with an adequate explanans of the behavior, we need to appeal to the second candidate, which Enc believes does provide us with an adequate explanans. One problem here is that Enc does not fairly represent the first, nonhistorical candidate explanans for competition with his preferred second, historical explanans.

Let us illustrate this alleged unfairness with Enc's primary example of the pigeon that is conditioned to peck a key when a light flashes in order to receive food if the key is pressed while the light is flashing. This behavior is indeed multiply realizable by different muscle movements and limb trajectories that are directed toward the more general goal of pecking the key (and receiving food), as opposed to some more specific goal that consists in one particular set of muscle movements and limb trajectories through which the pigeon pecks the key. The functional characterization of this behavior is what Enc means by "molar units of behavior". How can we understand these molar units of behavior? If the only nonhistorical properties that we know of this behavior are those of the pigeon's muscles and limbs, then knowledge of the historical properties about the pigeon's past conditioning are indispensable for understanding the behavior and we can use the indispensability argument to conclude that these historical properties are essential to the behavior.

However, suppose that we have knowledge of the nonhistorical properties of the pigeon's nervous system and environment in addition to knowledge of the nonhistorical properties of the pigeon's muscles and limbs. These additional nonhistorical properties constitute the more fair nonhistorical candidate that Enc fails adequately to consider. In this case, using the evidence from Sect. 3.2 against the idealized agent interpretation of the indispensability argument, we can argue that, in principle if not in practice (and in the future if not in the present), we can explain the pigeon's molar behavior without any need for knowledge about the history of conditioning. We can argue in this way because what does the causal work in generating the molar behavior are the causally active nonhistorical properties (Enc 1995, pp. 528-529; Enc and Adams 1992, pp. 649-651). The nonhistorical properties of the muscles and limbs do indeed serve a partial causal role in generating the molar behavior and so are part of a good explanans. However, the nonhistorical properties of the nervous system that is connected to the muscles and limbs (combined with the nonhistorical properties of the environment), also serve a causal role, and these are the properties that make the behavior molar rather than singular. To be sure, Lauder (1995) argues that morpholog- 
ical and phylogenetic studies often do not generate accurate predictions about functional behavior because they often do not contain crucial information about motor programs in the central nervous system. In addition, we can imagine many cases in which what appear to be similar selection pressures and other relevant historical factors will, for various reasons, have resulted in nonhistorical properties with different dispositions that have different effects in operant conditioning. Sometimes historical properties can be misleading (Amundson and Lauder 1994, pp. 461-462; Godfrey-Smith 1994, pp. 357-358; Walsh 1996, pp. 559-561; Walsh and Ariew 1996, pp. 498-500).

Of course, if we lack adequate knowledge of the causally relevant nonhistorical properties, we can use knowledge of historical properties as helpful pointers to them. In such a case, we can use the actual agent interpretation of the indispensability argument to conclude that historical properties are essential to the behavior. The problem is that, according to this argument, whether the historical properties are essential to the behavior or not depends on how much knowledge of relevant nonhistorical properties we do and do not possess. As pointed out in Sect. 3.3, it seems implausible for the essential properties of things outside of our minds to depend on things inside our minds. The essential properties of things outside of our minds (and our bodies) should not depend on our epistemic needs and whether or not we happen to possess or lack adequate knowledge of the causally relevant nonhistorical properties.

Curiously, in an earlier paper co-authored with Fred Adams, Enc and Adams (1992, pp. 649-653) seem explicitly to acknowledge related points. In that paper they make clear that teleological considerations serve a strictly heuristic role in identifying structural (or dispositional) facts about certain nonhistorical properties, such as the behavioral plasticity or molar units that they produce. On this view, although molar behavior has a nonhistorical supervenient base, we need to understand the plastic, functional, teleological, or goal-directed nature of molar behavior in order adequately to understand, explain, manipulate, and predict it.

A crucial point that Enc and Adams miss here along with Enc, however, is that whether we need information about relevant historical properties in order to understand the plastic, functional, teleological, or goal-directed nature of molar behavior is a contingent matter that depends on how much information we have about relevant nonhistorical properties. Enc and Adams seem to miss this point for the same reason that Enc misses it: an unfair comparison between specific muscle movements and precisely describable limb trajectories (or between "external causes" and "behavioral effects", Enc and Adams 1992, p. 650), on the one hand, and an historically informed teleological conception of goal-directedness, on the other hand. As pointed out above in the case of Enc, a more fair comparison consists in contrasting the historical alternative with a nonhistorical one that includes all relevant nonhistorical properties, such as internal causes or properties of nervous systems as well as any causally relevant contemporaneous relational and extrinsic properties. Enc and Adams seem to claim that this is not possible, which is tantamount to premise two of the indispensability argument. Please note that the indispensability argument is discussed and argued against: here in Sect. 3.3.1, above in Sects. 3.2 and 3.3, and below in Sect. 3.3.2.

Enc (1995) goes one step further than Enc and Adams (1992). Enc (1995) stops using the term 'heuristic' and redefines the supervenience base of molar behavior to 
include essentially the historical properties. The additional data that he considers in the 1995 paper, however, does not appear to suggest that the historical properties serve anything more than a heuristic role which we may or may not need depending on our knowledge of relevant nonhistorical properties.

\subsubsection{Elder's version of the indispensability argument: another brief (and similar) case study}

Elder claims that certain historical properties are essential to the products of natural selection and similar copying processes. He calls these products members of 'copied kinds'. He bases his argument for this claim on a certain kind of warrant that we have for engaging in inductive practices generally, and in making accurate predictions particularly, about members of copied kinds (Elder 1995, pp. 516, 522; 1996, pp. 192, 194-196, 198; Griffiths 1996, pp. S5-S6; 1999, pp. 215-219). ${ }^{17}$

In order to understand Elder's examples, we need briefly to sketch which historical properties he believes are essential to members of copied kinds. Elder's detailed discussions come down to two kinds of relevant historical properties. The first kind involves a past process of copying from previous members that historically served specific useful functions. The second kind involves past cooperating devices of other copied kinds that helped produce the sort of effect for which the copying process selects. In other words, we are talking about the historical properties of a past copying process of a certain kind and a past environment of a certain kind. Roughly speaking, we are talking about the historical properties about past selection in virtue of which biological devices and human artifacts have 'proper functions' (Millikan 1989). These historical properties about past selection are supposed to (1) warrant predictions about members of copied kinds, and (2) be essential to members of copied kinds.

Two of the main examples that Elder uses to make these claims involve the mating dances of stickleback fish. The first example involves a mating dance of male sticklebacks whose proper function is the fertilization of female stickleback eggs. The second example involves a dance whose proper function is to mesmerize tasty flies so that it is easier for the fish to catch the flies for food.

As regards the first example, Elder (1995, p. 195; 1996, p. 522) argues that if and when variations arise in the egg laying dispositions of female sticklebacks, then we can warrantedly predict that the future choreographic details of male stickleback dances will differ in ways that are responsive to those changes in the females. As regards the second example, Elder (1996, p. 522) argues that if and when the neural routines of tasty flies become more sophisticated, we can warrantedly predict that the future choreographic details of the dances will differ in ways that are responsive to those changes in the flies.

\footnotetext{
17 In fairness, I should point out that Elder has continued to develop his views in a series of publications. For instance, see Elder (2004). Nonetheless, even in more recent work, Elder (2004, p. 133) refers back to the publications discussed here (Elder 1995, 1996) for support or elaboration. Still, to be fair, I should also point out that Elder continues to develop his views in numerous publications that deserve independent discussion.
} 
Elder (1995, p. 522; 1996, pp. 196, 198) also seems to use examples like these to make a similar point about warranted prediction. Suppose that the male sticklebacks from the first example developed their mating dance on another planet called Twin Earth, and that the sticklebacks from the second example developed their fly mesmerizing dance on Earth. On Earth, past dances often enough brought about the fertilization of stickleback eggs because the dances were performed in the presence of female sticklebacks that were disposed to respond by laying eggs. Similarly, on Twin Earth, past dances often enough helped the fish catch flies for food because the dances were performed in the presence of flies that were disposed to respond by hovering around the dance. Suppose further that the choreographic details of these stickleback dances are the same on Earth and Twin Earth.

If we transport the Twin Earth mating dance sticklebacks to Earth, we may expect them to end their dances with futile snapping at nonexistent flies, but we cannot warrantedly predict that the choreographic details of their dances will differ in response to variations in the egg laying dispositions of female sticklebacks. Similarly, if we transport the Earth fly mesmerizing dance sticklebacks to Twin Earth, we may expect them to end their dances with the untimely release of sperm, but we cannot warrantedly predict that the choreographic details of their dances will differ in response to variations in the neural routines of tasty flies.

In making these claims about what we can and cannot warrantedly expect or predict, Elder makes two assumptions. The first assumption is that we have adequate knowledge of three things: (1) the selective or copying history of each respective stickleback dance, (2) the features of the past environment that played one or more roles in the selection or copying processes of each dance, and (3) the features of the present environment that are similar and different in relevant ways from features of the past environment. The second assumption that Elder makes about what we can and cannot warrantedly expect or predict is that we do not have adequate knowledge of two things: (1) the nonhistorical properties of the sticklebacks that make causal contributions to their behavior, and (2) the features of the nonhistorical environment that make causal contributions to the stickleback behavior.

As explained in Sects. 3.2, 3.3, and 3.3.1, we have reason not to accept Elder's second assumption. As our information about the nonhistorical properties of the sticklebacks increases, our need to appeal to the historical properties of the sticklebacks in order to predict their behavior decreases. ${ }^{18}$ To be sure, in many cases we have reason not to accept Elder's first assumption. This is the point of exhibit (C) from Sect. 3.2. It is through the study of various nonhistorical properties that we learn about historical properties as we make inferences to facts about the past (Davies 2001, pp. 55-56, Chap. 5). Sometimes nonhistorical properties will serve as a better guide than historical properties even when our knowledge of nonhistorical properties is incomplete. For our knowledge of historical properties can be incomplete as well (Turner 2005). In these cases, experimental measurements, trial and error in conditioning, and studying nonhistorical properties may be useful if not required (Amundson and Lauder 1994, pp. 459-463; Lauder 1995; Davies 2001, pp. 119-120). The time and resources

$\overline{18}$ As noted in Sect. 3.3.1, Enc and Adams (1992, pp. 649-650) share Elder's skepticism about this claim. 
required for trial and error may be as costly as the time and resources required to determine the relevant historical properties and facts about past selection. The disvalue of these costs, and the level of time and resources involved, will vary in accordance with technology, theoretical understanding, and research interests.

Elder (1995, 1996), Enc and Adams (1992), and Enc (1995) focus on behavior and other products of historical processes that are functional. However, we can accept the functional features of their examples without accepting their conclusions about historical properties. ${ }^{19}$ The nonhistorical focus/approach need not object to or abandon the use of teleology and goal directedness in functional analysis. The nonhistorical focus holds that (1) historical properties are only sometimes instrumentally required for the requisite functional analysis, and (2) a wide set of nonhistorical properties that includes contemporaneous intrinsic, contemporaneous extrinsic, and contemporaneous relational properties is always causally responsible for any actual functional activity. ${ }^{20,21}$

Elder (1995, p. 517) asks “... what is it, in the intrinsic shape of the mating dance of a male stickleback fish, that gives this dance its characteristic role in the fertilization of eggs from the female stickleback? Clearly such questions do not have answers." The apparent strength of this statement derives from the narrow focus on the shape of the mating dance, just as the apparent strength of Enc's arguments derives from the focus on muscles and limbs. If we expand our focus to include all of the relevant nonhistorical properties, such questions have clear answers. If we expand our focus to include intrinsic properties of the male stickleback's nervous and reproductive systems as well as the environmental properties that consist in the intrinsic properties of the nervous and reproductive systems of any female sticklebacks in the male's environment, then we can see the role that the mating dance plays in the fertilization of eggs. If we have enough information about nonhistorical properties, we can see this role and make related predictions about it without any information about historical properties.

Elder (1996, p. 198) uses the same seemingly unfair comparison as Elder (1995, p. 517) and Enc (1995). Elder and Enc both compare choreographic motions, on the one hand, with choreographic motions and their history, on the other hand. As suggested in Sect. 3.3.1, a more fair comparison consists in choreographic motions along with many other relevant nonhistorical properties, on the one hand, and choreographic motions and relevant historical properties, on the other hand. The need for information about historical properties in explaining functional behavior and making accurate

\footnotetext{
19 For a nonhistorical account of function, see Cummins (1975, 2002) and Davies (2000). Davies (2001) contains my favored nonhistorical alternative to historical accounts of function. However, I intend my claims here to be neutral between alternative nonhistorical accounts. See Hardcastle (1999) for general discussion.

20 For further discussion, see Bechtel (1986) and Mundale and Bechtel (1996), and Bechtel and Mundale (1999).

21 These points need not rely on a false dichotomy between historical and nonhistorical accounts of function. As Enc and Adams (1992) argue, for instance, historical accounts of function (often) seem well suited to answering certain explanatory questions about populations, on the one hand, and nonhistorical accounts of function (often) seem well suited to answering certain explanatory questions about individual organisms or individual biological devices, on the other hand. This distinction is roughly analogous to the one adapted from Waters (1998) in Sect. 2 between generalizations about distributions and generalizations about causal regularities. Recall that historical properties are essential to generalizations about distributions and that nonhistorical properties are essential to generalizations about causal regularities.
} 
predictions about it arises on the former comparison but not the latter one. This need for information about historical properties is based on our contingent epistemic needs that change in accordance with our knowledge of nonhistorical properties. As suggested and explained in Sects. 3.3 and 3.3.1, it seems a plausible conjecture that the essential properties of things outside of our minds should not depend on the changing epistemic needs inside of our minds. If the former did depend on the latter, then the essential properties of things outside of our minds would change as our knowledge of nonhistorical properties changes, which seems implausible.

\section{Conclusion}

In the terms from Sect. 2, although historical properties are essential to the distribution of members of historical kinds, they are also essential to the distribution of members of eternal kinds. Similarly, although nonhistorical properties are essential to the causal behavior of members of eternal kinds, they are also essential to the causal behavior of members of historical kinds. Likewise, although historical properties may serve a heuristic role in predicting and explaining the causal behavior of members of historical kinds, they may also serve a heuristic role in predicting and explaining the causal behavior of members of eternal kinds. In other words, history makes the same difference to biological and psychological subjects as it does to other kinds of subjects. Thinking otherwise runs into the confusion and the dependence problems. The point is not that history is not special. The point is that history is equally special to all things in the world when it comes to their distributions and that people may or may not need knowledge of history when studying any causally active parts of the world, depending on how much information and knowledge they have or lack about the relevant nonhistorical properties contributing to the causal activity under study.

\section{References}

Amundson, R., \& Lauder, G. (1994). Function without purpose: The uses of causal role function in evolutionary biology. Biology and Philosophy, 9, 443-469. doi:10.1007/BF00850375.

Ariew, A. (2003). Ernst Mayr's 'ultimate/proximate' distinction reconsidered and reconstructed. Biology and Philosophy, 18, 553-565. doi:10.1023/A:1025565119032.

Bakker, T. C. M., \& Milinski, M. (1991). Sequential female choice and the previous male effect in sticklebacks. Behavioral Ecology and Sociobiology, 29, 205-210. doi:10.1007/BF00166402.

Bakker, T. C. M., \& Milinski, M. (1993). The advantages of being red: Sexual selection in the stickleback. Marine and Freshwater Behaviour and Physiology, 23, 287-300. doi:10.1080/ 10236249309378870.

Bechtel, W. (1986). Teleological functional analyses and the hierarchical organization of nature. In N. Rescher (Ed.), Teleology and natural science (pp. 26-48). Landham, MD: University Press of America.

Bechtel, W., \& Mundale, J. (1999). Multiple realizability revisited: Linking cognitive and neural states. Philosophy of Science, 66, 175-207. doi:10.1086/392683.

Bell, M. A. \& Foster, S. A. (Eds.). (1994). The evolutionary biology of the threespine stickleback. Oxford: Oxford University Press.

Bickle, J. (2006a). Reducing mind to molecular pathways: Explicating the reductionism implicit in current cellular and molecular neuroscience. Synthese, 151, 411-434. doi:10.1007/s11229-006-9015-2.

Bickle, J. (2006b). Ruthless reductionism in recent neuroscience. IEEE Transactions on Systems, Man and Cybernetics, Part C, 36, 134-140. doi:10.1109/TSMCC.2006.871130. 
Bickle, J. (2007). Ruthless reductionism and social cognition. Journal of Physiology-Paris, 101, 230-235. doi:10.1016/j.jphysparis.2007.11.009.

Bickle, J. (2008). Real reduction in real neuroscience: Metascience, not philosophy of science (and certainly not metaphysics!). In J. Hohwy \& J. Kallestrup (Eds.), Being reduced: New essays on reduction, explanation, and causation (pp. 34-51). Oxford: Oxford University Press.

Bickle, J., Avison, M., Schmithorst, V., Landreth, A., \& Holland, S. (2003). Bridging the cognitive-cellular neuroscience gap empirically: A study combining physiology, modeling and fMRI. Journal of Experimental \& Theoretical Artificial Intelligence, 15, 161-175. doi:10.1080/0952813021000055225.

Boyd, R. (1992). Constructivism, realism, and philosophical method. In J. Earman (Ed.), Inference, explanation, and other frustrations: Essays in the philosophy of science (pp. 131-198). Berkeley, CA: University of California Press.

Boyd. R. (1999a). Homeostasis, species, and higher taxa. In R. A. Wilson (Ed.), Species: New interdisciplinary essays. Cambridge, MA: MIT Press.

Boyd, R. (1999b). Kinds, complexity and multiple realization. Philosophical Studies, 95, 67-98. doi:10. 1023/A:1004511407133.

Boyd, R. (1999c). Kinds as the 'Workmanship of men': Realism, constructivism, and natural kinds. In J. Nida-Rümelin (Ed.), Rationalität, realismus, revision: Proceedings of the third international congress, Gesellschaft für Analytische Philosophie, de Gruyter (pp. 52-89).

Boyd, R. (2001). Reference, (in)commensurability and meanings: Some (perhaps) unanticipated complexities. In P. Hoyningen-Huene \& H. Sankey (Eds.), Incommensurability and related matters (pp. 1-63). Dordrecht: Kluwer.

Brooks, D., \& McLennan, D. (1991). Phylogeny, ecology, and behavior: A research program in comparative biology. Chicago, IL: University of Chicago Press.

Carter, W. R., \& Hestevold, H. S. (1994). On passage and persistence. American Philosophical Quarterly, 31, 269-284.

Chan, Y. F., Marks, M. E., Jones, F. C., Villarreal, G., Shapiro, M. D., \& Brady, S. D., et al. (2010). Adaptive evolution of pelvic reduction in sticklebacks by recurrent deletion of a Pitx1 enhancer. Science, 327, 302-305. doi:10.1126/science.1182213.

Colosimo, P., Hosemann, K., Balabhadra, S., Villareal, G., Dickson, M., \& Grimwood, J., et al. (2005). Widespread parallel evolution in sticklebacks by repeated fixation of ectodysplasin alleles. Science, 307, 1928-1933. doi:10.1126/science.1107239.

Colosimo, P., Peichel, C., Nereng, K., Blackman, B., Shapiro, M., \& Schluter, D., et al. (2004). The genetic architecture of parallel armor plate reduction in threespine sticklebacks. PLoS Biol, 2(5), E109. doi:10. 1371/journal.pbio.0020109.

Cummins, R. (1975). Functional analysis. Journal of Philosophy, 72, 741-765.

Cummins, R. (2002). Neo-teleology. In R. Cummins, A. Ariew, \& M. Perlman (Eds.), Functions: New essays in the philosophy of psychology and biology (pp. 157-173). Oxford: Oxford University Press.

Davies, P. S. (1996). Discovering the functional mesh: On the methods of evolutionary psychology. Minds and Machines, 6, 559-585. doi:10.1007/BF00389659.

Davies, P. S. (2000). The nature of natural norms: Why selected functions are systemic capacity functions. Nous, 34, 85-107. doi:10.1111/0029-4624.00203.

Davies, P. S. (2001). Norms of nature: Naturalism and the nature of functions. Cambridge, MA: MIT Press.

Dretske, F. (1998). Action and autonomy. In J. Norton \& J. Earman (Eds.), Cosmos of science (pp. 515529). Pittsburgh, PA: University of Pittsburgh Press.

D'Zmura, M., Deng, S., Lappas, T., Thorpe, S., \& Srinivasan, R. (2009). Toward EEG sensing of imagined speech. In J. A. Jacko (Ed.), Human-computer interaction: New trends, part I, HCII 2009, LNCS 5610 (pp. 40-48). Berlin: Springer. doi:10.1007/978-3-642-02574-7_5.

Elder, C. (1995). A different kind of natural kind. Australasian Journal of Philosophy, 73, 516-531. doi:10. 1080/00048409512346871.

Elder, C. (1996). On the reality of medium-sized objects. Philosophical Studies, 83, 191-211. doi:10. 1007/BF00354288.

Elder, C. (2004). Real natures and familiar objects. Cambridge, MA: MIT Press.

Enc, B. (1995). Units of behavior. Philosophy of Science, 62, 523-542. doi:10.1086/289884.

Enc, B., \& Adams, F. (1992). Functions and goal directedness. Philosophy of Science, 59, 635-654. doi:10. $1086 / 289699$. 
Fitzgerald, G. J. (1993). Seeing red, turning red. Reviews in Fish Biology and Fisheries, 3, 286-292. doi:10. 1007/BF00043931.

Garfinkel, A. (1981). Forms of explanation. New Haven, CT: Yale University Press.

Godfrey-Smith, P. (1994). A modern history theory of functions. Nous, 28, 344-362.

Grantham, T., \& Nichols, S. (1999). Evolutionary psychology: Ultimate explanations and Panglossian predictions. In V. G. Hardcastle (Ed.), Where biology meets psychology: Philosophical essays (pp. 47-66). Cambridge, MA: MIT Press.

Griffiths, P. E. (1996). Darwinism, process structuralism and natural kinds. Philosophy of Science, 63(Supplement: PSA 1996 Contributed Papers), S1-S9. doi:10.1086/289930

Griffiths, P. E. (1997). What emotions really are: The problem of psychological categories. Chicago, IL: University of Chicago Press.

Griffiths, P. E. (1999). Squaring the circle: Natural kinds with historical essences. In R. A. Wilson (Ed.), Species: New interdisciplinary essays. Cambridge, MA: MIT Press.

Hardcastle, V. G. (1999). Understanding functions: A pragmatic approach. In V. G. Hardcastle (Ed.), Where biology meets psychology: Philosophical essays. Cambridge, MA: MIT Press.

Haynes, J. (2008). Detecting deception from neuroimaging signals - a data-driven perspective. Trends in Cognitive Sciences, 12, 126-127. doi:10.1016/j.tics.2008.01.003.

Haynes, J. (2009). Decoding visual consciousness from human brain signals. Trends in Cognitive Sciences, 13, 194-202. doi:10.1016/j.tics.2009.02.004.

Haynes, J., \& Rees, G. (2006). Decoding mental states from brain activity in humans. Nature Reviews Neuroscience, 7, 523-534. doi:10.1038/nrn1931.

Haynes, J., Sakai, K., Rees, G, Gilbert, S., Frith, C., \& Passingham, R. (2007). Reading hidden intentions in the human brain. Current Biology, 17, 323-328. doi:10.1016/j.cub.2006.11.072.

Hendry, A., Bolnick, D., Berner, D., \& Peichel, C. (2009). Along the speciation continuum in stickleback. Journal of Fish Biology, 75, 2000-2036. doi:10.1111/j.1095-8649.2009.02419.x.

Ishikawa, M., \& Mori, S. (2000). Mating success and male courtship behaviors in three populations of the threespine stickleback. Behaviour, 137, 1065-1080. doi:10.1163/156853900502439.

Ishikawa, M., Mori, S., \& Nagata, Y. (2006). Intraspecific differences in patterns of courtship behaviours between the Pacific Ocean and Japan Sea forms of the three-spined stickleback. Journal of Fish Biology, 69, 938-944. doi:10.1111/j.1095-8649.2006.01135.x.

Just, M. A., Cherkassky, V. L., Aryal, S., \& Mitchell, T. M. (2010). A neurosemantic theory of concrete noun representation based on the underlying brain codes. PLOS ONE, 5, e8622. doi:10.1371/journal. pone.0008622.

Kasting, J., \& Catling, D. (2003). Evolution of a habitable planet. Annual Review of Astronomy and Astrophysics, 41, 429-463. doi:10.1146/annurev.astro.41.071601.170049.

Kay, K. N., \& Gallant, J. L. (2009). I can see what you see. Nature Neuroscience, 12, 245-246. doi:10. 1038/nn0309-245.

Kay, K. N., Naselaris, T., Prenger, R. J., \& Gallant, J. L. (2008). Identifying natural images from human brain activity. Nature, 452, 352-355. doi:10.1038/nature06713.

Kim, J. (1991). Dretske on how reasons explain behavior. In B. McLaughlin (Ed.), Dretske and his critics (pp. 52-72). Cambridge, MA: Blackwell.

Kingsley, D., \& Peichel, C. (2007). The molecular genetics of evolutionary change in sticklebacks. In S. Ostlund-Nilsson, I. Mayer, \& F. A. Huntingford (Eds.), Biology of the three-spine stickleback (pp. 41-81). Boca Raton, FL: CRC Press.

Kitano, J., Mori, S., \& Peichel, C. (2007). Phenotypic divergence and reproductive isolation between sympatric forms of Japanese threespine sticklebacks. Biological Journal of the Linnean Society, 91, 671-685. doi:10.1111/j.1095-8312.2007.00824.x.

Kitano, J., Mori, S., \& Peichel, C. (2008). Divergence of male courtship displays between sympatric forms of anadromous threespine stickleback. Behaviour, 145, 443-461. http://www.brill.nl/beh.

Kitano, J., Ross, J. A., Mori, S., Kume, M., Jones, F. F., \& Chan, Y. F., et al. (2009). A role for a neo-sex chromosome in stickleback speciation. Nature, 461, 1079-1083. doi:10.1038/nature08441.

Kump, L. R., Kasting, J., \& Crane, R. (2004). The Earth system. Upper Saddle River, NJ: Prentice Hall.

Lauder, G. V. (1995). On the inference of function from structure. In J. J. Thomason (Ed.), Functional morphology and vertebrate paleontology (pp. 1-18). New York: Cambridge University Press.

McKinnon, J., Mori, S., Blackman, B., Kingsley, D., Jamieson, L., \& Chou, J., et al. (2004). Evidence for ecology's role in speciation. Nature, 429, 294-298. doi:10.1038/nature02556. 
McKinnon, J. S., \& Rundle, H. D. (2002). Speciation in nature: The threespine stickleback model systems. Trends in Ecology \& Evolution, 17, 480-488. doi:10.1016/S0169-5347(02)02579-X.

McKitrick, J. (2003). A case for extrinsic dispositions. Australasian Journal of Philosophy, 81, 155-174. doi:10.1080/713659629.

McLennan, D. (1991). Integrating phylogeny and experimental ethology: From pattern to process. Evolution, 45, 1773-1789. http://www.jstor.org/stable/2409831.

McLennan, D. (1993). Phylogenetic relationships in the Gasterosteidae: An updated tree based on behavioral characters with a discussion of homoplasy. Copeia, 1993(2), 318-326. http://www.jstor. org/stable/1447132.

McLennan, D. (2007). The umwelt of the three-spined stickleback. In S. Ostlund-Nilsson, I. Mayer, \& F. A. Huntingford (Eds.), Biology of the three-spine stickleback (pp. 179-224). Boca Raton, FL: CRC Press.

McLennan, D., Brooks, D., \& McPhail, J. D. (1988). The benefits of communication between comparative ethology and phylogenetic systematics: A case study using gasterosteid fishes. Canadian Journal of Zoology, 66, 2177-2190. doi:10.1139/z88-325.

McLennan, D., \& McPhail, J. D. (1989a). Experimental investigations of the evolutionary significance of sexually dimorphic nuptial colouration in Gasterosteus aculeatus (L.): Temporal changes in the structure of the male mosaic signal. Canadian Journal of Zoology, 67, 1767-1777. doi:10.1139/ z89-253.

McLennan, D., \& McPhail, J. D. (1989b). Experimental investigations of the evolutionary significance of sexually dimorphic nuptial colouration in Gasterosteus aculeatus (L.): The relationship between male colour and male behaviour. Canadian Journal of Zoology, 67, 1778-1782. doi:10.1139/ z89-254.

Merricks, T. (1994). Endurance and indiscernibility. Journal of Philosophy, 91, 165-184.

Merricks, T. (1995). On the incompatibility of enduring and perduring entities. Mind, 104, 523-531. doi:10. 1093/mind/104.415.521.

Merricks, T. (1999). Persistence, parts, and presentism. Nô̂s, 33, 421-438. doi:10.1111/0029-4624. 00162.

Milinski, M., \& Bakker, T. C. M. (1990). Female sticklebacks use male coloration in mate choice and hence avoid parasitized males. Nature, 344, 330-333. doi:10.1038/344330a0.

Miller, R. W. (1978). Methodological individualism and social explanation. Philosophy of Science, 45, 387-414. doi:10.1086/288814.

Miller, C., Beleza, S., Pollen, A., Schluter, D., Kittles, R., Shriver, M., \& Kingsley, D. (2007). cis-Regulatory changes in Kit Ligand expression and parallel evolution of pigmentation in sticklebacks and humans. Cell, 131, 1179-1189. doi:10.1016/j.cell.2007.10.055.

Millikan, R. (1989). In defense of proper functions. Philosophy of Science, 56, 288-302. doi:10.1086/ 289488.

Millikan, R. (1996). On swampkinds. Mind \& Language, 11, 103-117. doi:10.1111/j.1468-0017.1996. tb00035.x.

Millikan, R. (1999). Historical kinds and the special sciences. Philosophical Studies, 95, 45-65. doi:10. 1023/A:1004532016219.

Millikan, R. (2000). On clear and confused ideas: An essay about substance concepts. Cambridge: Cambridge University Press.

Mitchell, T. M., Shinkareva, S. V., Carlson, A., Chang, K.-M., Malave, V. L., \& Mason, R. A., et al. (2008). Predicting human brain activity associated with the meanings of nouns. Science, 320, 1191-1195. doi:10.1126/science.1152876.

Mundale, J., \& Bechtel, W. (1996). Integrating neuroscience, psychology, and evolutionary biology through a teleological conception of function. Minds and Machines, 6, 481-505. doi:10.1007/ BF00389655.

Naselaris, T., Prenger, R., Kay, K., Oliver, M., \& Gallant, J. (2009). Bayesian reconstruction of natural images from human brain activity. Neuron, 63, 902-915. doi:10.1016/j.neuron.2009.09.006.

Palatucci, M., Pomerleau, D. A., Hinton, G. E., \& Mitchell, T. (2009). Zero-shot learning with semantic output codes. In Y. Bengio, D. Schuurmans, J. Lafferty, C. K. I. Williams, \& A. Culotta (Eds.), Advances in neural information processing systems, (vol. 22, pp. 1410-1418).

Papineau, D. (2001). The rise of physicalism. In C. Gillett \& B. Loewer (Eds.), Physicalism and its discontents (pp. 3-36). Cambridge: Cambridge University Press. 
Papineau, D. (2009). The causal closure of the physical and naturalism. In B. McLaughlin, A. Beckermann, \& S. Walter (Eds.), The Oxford handbook of philosophy of mind (pp. 53-65). Oxford: Oxford University Press.

Pelkwijk, J., \& Tinbergen, N. (1937). Eine reizbiologische Analyse einiger Verhaltensweisen von Gasterosteus aculeatus L. Zeitschrift Für Tierpsychologie, 1, 193-203.

Press, F., Siever, R., Jordan, T., \& Grotzinger, J. (2003). Understanding Earth (4th ed.). New York: W.H. Freeman Company.

Prior, E., Pargetter, R., \& Jackson, F. (1982). Three theses about dispositions. American Philosophical Quarterly, 19, 251-259.

Rowe, M., Baube, C., Loew, E., \& Phillips, J. (2004). Optimal mechanisms for finding and selecting mates: How threespine stickleback (Gasterosteus aculeatus) should encode male throat colors. Journal of Comparative Physiology A: Neuroethology, Sensory, Neural, and Behavioral Physiology, 190, 241256. doi:10.1007/s00359-004-0493-8.

Rowland, W. (1984). The relationships among nuptial coloration, aggression, and courtship in male threespine sticklebacks. Canadian Journal of Zoology, 62, 999-1004. doi:10.1139/z84-141.

Rowland, W. (1994). The proximal basis of stickleback behavior: An evolutionary perspective. In M. A. Bell \& S. A. Foster (Eds.), The evolutionary biology of the threespine stickleback (pp. 297-344). Oxford: Oxford University Press.

Rowland, W., \& Sevenster, P. (1985). Sign stimuli in sticklebacks (Gasterosteus aculeatus): A re-examination and extension of some classic experiments. Behaviour, 93, 241-257. doi:10. $1163 / 156853986$ X00919.

Saidel, E. (2001). Teleosemantics and the epiphenomenality of content. Canadian Journal of Philosophy Supplement, 27, 139-166.

Schluter, D., Marchinko, K. B., Barrett, R. D. H., \& Rogers, S. M. (2010). Natural selection and the genetics of adaptation in threespine stickleback. Philosophical Transactions of the Royal Society B: Biological Sciences, 65, 2479-2486. doi:10.1098/rstb.2010.0036.

Shapiro, M., Bell, M., \& Kingsley, D. (2006). Parallel genetic origins of pelvic reduction in vertebrates. Proceedings of the National Academy of Sciences, 103, 13753-13758. doi:10.1073/pnas. 0604706103.

Shapiro, M., Marks, M., Peichel, C., Blackman, B., Nereng, K., \& Jónsson, B., et al. (2004). Genetic and developmental basis of evolutionary pelvic reduction in threespine sticklebacks. Nature, 428, 717-723. doi:10.1038/nature02415.

Shapiro, M., Summers, B., Balabhadra, S., Aldenhoven, J., Miller, A., \& Cunningham, C., et al. (2009). The genetic architecture of skeletal convergence and sex determination in ninespine sticklebacks. Current Biology, 19, 1140-1145. doi:10.1016/j.cub.2009.05.029.

Shinkareva, S. V., Mason, R. A., Malave, V. L., Wang, W., Mitchell, T. M., \& Just, M. A. (2008). Using fMRI brain activation to identify cognitive states associated with perception of tools and dwellings. PLoS One, 3, e1394, 1-9. doi:10.1371/journal.pone.0001394.

Shoemaker, S. (1980). Causality and properties. Reprinted in Shoemaker, S. (2003). Identity, cause, and mind: Philosophical essays, expanded edition (pp. 206-233). Oxford: Oxford University Press.

Slutsky, D. (2001). Causally inefficacious moral properties. Southern Journal of Philosophy, 39, 595-610. doi:10.1111/j.2041-6962.2001.tb01835.x.

Sober, E. (1995). Natural selection and distributive explanation: A reply to Neander. British Journal for the Philosophy of Science, 46, 384-397. doi:10.1093/bjps/46.3.384.

Srinivasan, R., Thorpe, S., Deng, S., Lappas, T., \& D'Zmura, M. (2009). Decoding attentional orientation from EEG spectra. In J. A. Jacko (Ed.), Human-computer interaction, new trends, part I, HCII 2009, LNCS 5610 (pp. 176-183). Berlin: Springer. doi:10.1007/978-3-642-02574-7_20.

Tinbergen, N. (1951). The study of instinct. Oxford: Oxford University Press.

Tinbergen, N. (1952). The curious behavior of the stickleback. Scientific American, 187, 22-26.

Turner, D. (2005). Local underdetermination in historical science. Philosophy of Science, 72, 209-230. doi:10.1086/426851.

Walsh, D. (1996). Fitness and function. British Journal for the Philosophy of Science, 47, 553-574. doi:10. 1093/bjps/47.4.553.

Walsh, D. (1999). Alternative individualism. Philosophy of Science, 66, 628-648. doi:10.1086/392758.

Walsh, D., \& Ariew, A. (1996). A taxonomy of functions. Canadian Journal of Philosophy, 26, 493-514. 
Waters, C. K. (1998). Causal regularities in the biological world of contingent distributions. Biology and Philosophy, 13, 5-36. doi:10.1023/A:1006572017907.

Wilz, K. J. (1970). Causal and functional analysis of dorsal pricking and nest activity in the courtship of the three-spined stickleback Gasterosteus aculeatus. Animal Behavior, 18, 115-124.

Wooton, R. J. (1976). The biology of the sticklebacks. New York: Academic Press.

Wooton, R. J. (1984). A functional biology of sticklebacks. Berkeley, CA: University of California Press. 